\title{
El maestro de obras llanisco Manuel Pesquera y la construcción de la iglesia de Santo Tirso de Villahibiera en León (1779-1783)
}

\author{
Jorge Martínez Montero \\ Escuela Superior de Conservación y Restauración \\ de BB.CC. de León
}

RESUMEN:

La iglesia parroquial de Santo Tirso de Villahibiera es considerada un referente desde tiempo inmemorial en la arquitectura religiosa a orillas del río Esla. La presente investigación pone de manifiesto la historia constructiva del templo, dando a conocer la ampliación llevada a cabo entre los años 1779 y 1783, bajo la dirección del maestro de obras Manuel Pesquera, constituyendo un testimonio inédito del maestro llanisco en la provincia de León.

PALABRAS CLAVE:

Arquitectura religiosa, siglo XVIII, Santo Tirso, Villahibiera, León.

\section{ABSTRACT:}

The parish church of Santo Tirso de Villahibiera is considered a benchmark since time immemorial in the religious architecture on the banks of the river Esla. The present investigation shows the construction history of the temple, announcing the expansion carried out between 1779 and 1782, under the direction of master builder Manuel Pesquera, constituting an unprecedented testimony of llanisco master in the province of León.

\section{KEYWORDS:}

Religious architecture, XVI century, Santo Tirso, Villahibiera, León. 


\section{Villahibiera y su primitiva iglesia románica}

El municipio de Villahibiera se encuentra situado al noreste de la provincia de León, a orillas del río Corcos y en la región del alto Esla, a una distancia aproximada de $46 \mathrm{~km}$ con respecto a la capital leonesa ${ }^{1}$. Históricamente ha contado con numerosas denominaciones, todas ellas con un mismo origen etimológico, entre las que figuran Villa de Vera, Villa de Bera, Villa Dibiera, Villadibera, Villadebiera, Villa viera, Villaibiera o la actual de Villahibiera.

El académico Aurelio Calvo, en su ya clásica obra sobre el monasterio y pueblos del concejo de Gradefes, recoge numerosos testimonios documentales de ventas, donaciones y mandas testamentarias, alusivos a la reiterada presencia del pueblo desde principios del siglo X hasta bien entrado el siglo $\mathrm{XIII}^{2}$. Mientras que desde el año 1439, perteneciente ya a la jurisdicción de la villa de Rueda del Almirante, Villahibiera era considerado uno de los cuarenta y dos lugares que se encontraban bajo la potestad del almirante de Castilla D. Fadrique Enríquez ${ }^{3}$.

De este periodo de actividad, data la construcción de la capilla eremitoria o iglesia monasterial, entendida como el germen de la iglesia parroquial de Santo Tirso y considerada uno de los escasos vestigios del románico rural leonés, datada por los historiadores en el siglo XII ${ }^{4}$.

En relación a la escasa bibliografía existente sobre el pueblo y su iglesia, véase: CALVO ALONSO, Aurelio, El Monasterio de Gradefes. Apuntes para su historia y la de algunos otros cenobios y pueblos del concejo, León, Imprenta provincial, 1936-1945, pp. 110-111; ALONSO GONZÁLEZ, Joaquín Miguel, Ruta de los monasterios en la tierra de Sollanzo (entre los ríos Porma y Esla, León), León, Asociación Intermunicipal Esla-Rueda, 2004, p. 115.

2 CALVO AlONSO, Aurelio, El Monasterio de Gradefes. Apuntes para su historia y la de algunos otros cenobios y pueblos del concejo, op. cit., pp. 108-109.

3 Ibidem., p. 69; URDIALES LARED0, Eduardo, Historia de la villa y tierra de Rueda del Almirante, León, [s.n.], 2001, pp. 8-11; GALLEG0 DÍEZ, Mario, Historia de la parroquia y el concejo de Quintanas de Rueda, León, Ayuntamiento de Valdepolo, 2002, pp. 20-23.

4 Sobre la capilla eremitoria de Santo Tirso, consúltese: ÁlVAREZ GARCÍA, María José, Románico rural de cabecera plana en el nordeste de León, León, Diputación Provincial, Institución Fray Bernardino de Sahagún, 1990, pp. 107-110; GARCÍA GUINEA, Miguel Ángel y PÉREZ GONZÁLEZ, José María, (coords.), Enciclopedia del Románico en Castilla y León: León, Aguilar de Campoo, Fundación Santa María la Real, Centro de Estudios del Románico, 2002, pp. 629-634.
Realizada en mampostería de piedra, reforzada en sus esquinas por sillares escuadrados, tejado a dos aguas y alero con canecillos, ocupa una superficie exterior de $48 \mathrm{~m}^{2}$ y su referente más cercano lo encontramos en el ábside de la iglesia de Villarmún ${ }^{5}$. Al interior, presenta una nave rectangular con cubierta de bóveda de cañón corrido, a la que se accedía mediante un arco de medio punto peraltado del que actualmente se conservan sus arranques; un espacio que pasó a utilizarse como sacristía, a cuyos pies se alza una torre de sillar y mampostería a cuatro aguas, con tres niveles de altura; el tercero, posterior en ejecución, está realizado en ladrillo visto y presenta, como el resto de los niveles, pequeños vanos de medio punto distribuidos irregularmente (Fig. 1) ${ }^{6}$.

\section{La nueva iglesia parroquial: proceso de fábrica y ornamentación interior}

La obra de la iglesia de Villahibiera da comienzo a finales del siglo XVI, momento de expansión en la diócesis leonesa en que empiezan a levantarse numerosas parroquias a orillas del río Esla, tal es el caso de la cercana iglesia de San Miguel arcángel en la localidad de Cubillas de Rueda (1562-1602) 7 . Si bien, nada se ha conservado del proceso de fábrica inicial, es muy probable que se tratara de un templo

CALVO ALONSO, Aurelio, El Monasterio de Gradefes. Apuntes para su historia y la de algunos otros cenobios y pueblos del concejo, op. cit., p. 111; ÁLVAREZ GARCÍA, María José, Románico rural de cabecera plana en el nordeste de León, op. cit., pp. 103-106.

6 A cerca de la particularidad de las torres en las iglesias románicas del ámbito leonés, como las de San Miguel de Escalada y San Martín de Valdetuéjar, véase: VALDÉS FERNÁNDEZ, Manuel, Arquitectura mudéjar en León y Castilla, León, Colegio Universitario de León, Institución Fray Bernardino de Sahagún C.S.I.C., 1981, pp. 59-60; HERRÁEZ ORTEGA, María Victoria, "Arte románico en la cuenca de río Esla (I) Arquitectura”, en Tierras de León, 48, León, 1982, pp. 89-90; ÁLVAREZ GARCÍA, María José, Románico rural de cabecera plana en el nordeste de León, op. cit., pp. 58-59.

7 El proceso constructivo de la iglesia ha sido analizado por: MARTÍNEZ MONTERO, Jorge, "Obras en la iglesia de San Miguel de Cubillas de Rueda (León)”, en De Arte, 13, León, 2014, pp. 75-94; MARTÍNEZ MONTERO, Jorge; CACHALDORA RODRÍGUEZ, Marcos, "Investigación e intervención: la restauración del retablo colateral de la iglesia parroquial de Cubillas de Rueda (León)", en El conservador-restaurador de patrimonio cultural: experiencias de preservación e intervención en la obra de arte, León, Universidad, Fuescyl, 2014, pp. 124-125. 

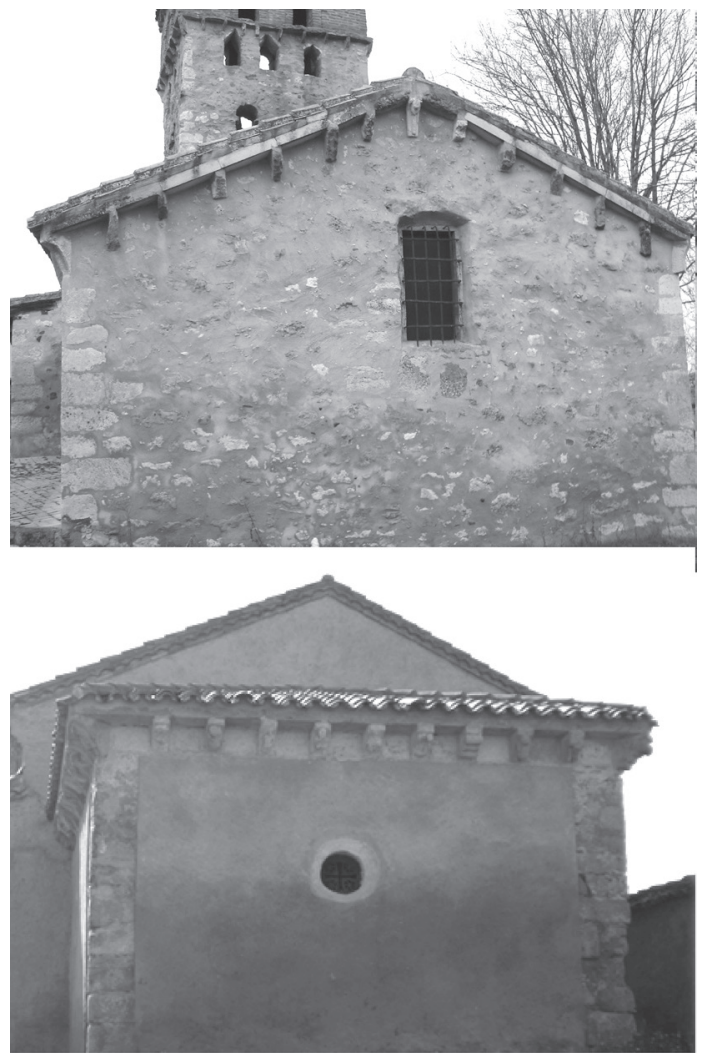

Fig. 1. Vista exterior de la capilla de la iglesia de Santo Tirso de Villahibiera y de la capilla de la iglesia de Nuestra Señora de la Asunción de Villarmún, León. Fotografías del autor.

de tres naves y cabecera recta, emplazado a los pies de la propia capilla románica (Fig. 2) ${ }^{8}$.

En la centuria siguiente, el altar mayor de la iglesia contaba con un retablo bajo la advocación del patrón Santo Tirso, una obra que fue realizada entre los años 1683 y 1687 por el ensamblador trasmerano Francisco de Uriarte, dorado y policromado por el leonés Manuel de Valladolid, tarea por la que este último cobró la cantidad de 10.200 reales $^{9}$. Un trabajo que Uriarte compaginó con la hechura del retablo

8 El Archivo de la Iglesia de Santo Tirso de Villahibiera (citado en adelante como AITV) custodia la siguiente documentación: 1 Libro de fábrica (1623-1686), $2^{\circ}$ Libro de fábrica (1687-1754), $3^{\circ}$ Libro de fábrica (1754-1850), 4 Libro de fábrica (1850-1892), 5 Libro de fábrica (1893-1968), Libro de la fábrica del glorioso apóstol San Pedro de los Balmatados propio de este lugar de Villa de Viera (1675-1782).

9 AITV. $2^{\circ}$ Libro de fábrica, 18 de junio de 1687 , s. f. Mayordomo Juan Fernández. "Primeramente se le reçive en data çiento y nobenta y dos reales y medio que dio Francisco Uriarte ensamblador con que se acabó de pagar el retablo".

"Más dieç mill y dosçientos reales que dio a Manuel de Valladolid por dorar el retablo del altar mayor".

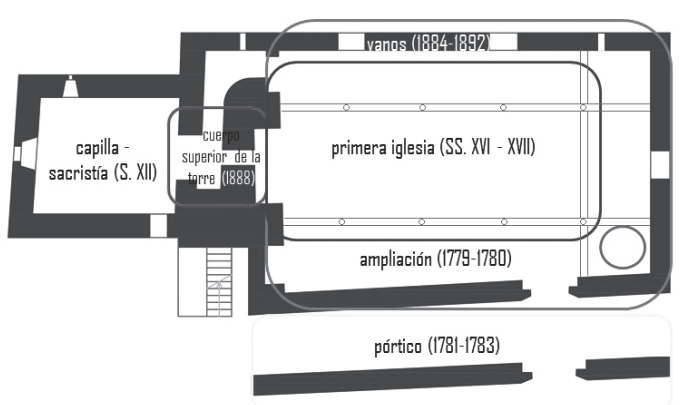

Fig. 2. Interpretación en planta de las diferentes fases constructivas de la iglesia de Santo Tirso de Villahibiera, León. Diseño del autor.

mayor del cercano santuario de la Virgen de la Velilla, en La Mata de Monteagudo (1684-1691) $\mathrm{y}$ en la que Valladolid hace compatible con su labor al frente del retablo colateral de Nuestra Señora del Rosario para la iglesia de Oteruelo de la Valdoncina $(1686)^{10}$.

Es ahora cuando se llevan a cabo profundas transformaciones en la iglesia, tal y como se desprende de los descargos del año 1700, en los que figuran importantes cantidades abonadas a los carpinteros por diversas obras de carácter estructural, coincidiendo con la construcción aledaña de la panera para la recogida y almacenamiento de los granos ${ }^{11}$. Entre los años 1711 y 1714 se realiza la apertura de un tragasol en el altar mayor, ornado todo él junto al dorado de los arcos interiores del templo, a la par que se efectúan nuevas reformas, como la elevación

10 LLAMAZARES RODRÍGUEZ, Fernando, El retablo barroco en la provincia de León, León, Universidad, 1991, p. 208; LLAMAZARES RODRÍGUEZ, Fernando, Fuentes documentales para el arte barroco en la provincia de León. Ensambladores, escultores y pintores, León, Universidad, 2008, p. 190.

11 AITV. $2^{\circ}$ Libro de fábrica, 12 de julio de 1700, s. f. Mayordomo Pedro del Cano. "Primeramente da en data veinte y seis reales que pagó de diez y seis tablas que se compraron en Sorriba para la obra de la iglesia".

"Más ochenta y seis reales y medio de clabaçón para la obra".

"Más mil y setenta reales que llevaron los carpinteros por la obra que içieron en la iglesia”.

"Más de texa para la iglesia y de traerla ciento treinta y cuatro reales y medio".

AITV. $2^{\circ}$ Libro de fábrica, 8 de julio de 1711, s. f. Mayordomo Juan Andrés. "Más se le pasan a dicho mayordomo trecientos y setenta y nuebe reales que tubo de costo el haçer las paredes de la panera de la obra de manos a los canteros en que se ocuparon veinte y siete dias que ganaban sus personas a dos reales y medio...". 
de la sacristía en 1717 o el revoco exterior de la torre en $1724^{12}$.

El 30 de junio de 1722, con motivo de la visita del obispo de León D. Martín de Zalayeta al templo, quien manda se haga inventario de los bienes de la iglesia, conocemos que la parroquia contaba entre otras alhajas con "tres chrismeras de plata, una cruz de plata con su santo christo de lo mismo con su manga de damasco encarnado, un pendón bueno de damasco encarnado y su cruz al remate, dos andas, un púlpito nuevo, un confesonario, tres misales, dos manuales, dos capas, una muceta para llevar el viático, un paño para el atril, cinco casullas, dos cálices buenos con sus patenas, más tres frontales, más otro frontal para el altar de Nuestra Señora quando se anda su procesión..."13. Todo un conjunto de ornamentos que se recogen de nuevo en el inventario efectuado por orden de la visita a la iglesia en el año 1749, del obispo D. José de Lupia y de Roger ${ }^{14}$.

Como parte integrante de los mismos, figura una cruz procesional realizada en la segunda mitad del siglo XVI y atribuida a seguidores de Enrique de Arfe; una pieza trabajada en madera, plata, cobre y plata sobredorada, que es rehecha durante los años 1735 y 1736, labor por la que "se le revajan mil duzientos y doze reales al que importó la compostura de la cruz de plata con diferentes piezas que se le hecharon" ${ }^{15}$.

12 AITV. $2^{\circ}$ Libro de fábrica, 21 de septiembre de 1712, s. f. Mayordomo Miguel de Valdeubieco. "Más ciento $y$ setenta y nueve reales que tubo de costo el hazer el tragasol al altar mayor".

AITV. 20 Libro de fábrica, 24 de junio de 1715, s. f. Mayordomo Andrés de la Mata. "Iden doscientos reales que costó dorar los arcos de la iglesia, pintar el tragasol de la capilla maior".

AITV. $2^{\circ}$ Libro de fábrica, 1 de septiembre de 1717 , s. f. Mayordomo Antonio Fernández. “Más cinco reales de un despacho de el señor provisor para haçer la sacristia".

AITV. $2^{\circ}$ Libro de fábrica, 31 de agosto de 1724, s. f. Mayordomo Baltasar de la Puente. "Más cinquenta y siete reales que tubo de costo rebocar la torre".

13 AITV. 20 Libro de fábrica, Gradefes, 30 de junio de 1722, s. f. Visita del obispo de León D. Martín de Zelayeta.

14 AITV. $2^{\circ}$ Libro de fábrica, Palacio de Rueda, 16 de mayo de 1749 , s. f. Visita del obispo de León D. José de Lupia y de Roger.

15 AITV. $2^{\circ}$ Libro de fábrica, 11 de julio de 1735 , s. f. Mayordomo Pedro Fernández. "Iten se le revajan siete reales y diez maravedies los mismos que gastó en el camino cuando llevó la cruz de plata a León”.

AITV. $2^{\circ}$ Libro de fábrica, 22 de noviembre de 1736, s. f. Mayordomo Andrés de la Mata. "Iten setenta y tres reales que costó la caja para la dicha cruz".
El programa devocional se completaba con dos altares y sus correspondientes retablos colaterales, bajo la advocación de Nuestra Señora y Santa Eugenia (1740-1741), que fueron repintados entre los años 1762 y $1763^{16}$. Dos imágenes con las que poder afianzar la fe de sus parroquianos, quienes verían reforzadas sus creencias a través de la fundación de las cofradías de Sancti Spiritus y Santa Eugenia ${ }^{17}$.

\section{Manuel Pesquera y la ampliación de la iglesia de Villahibiera}

A mediados de la década de los setenta del siglo XVIII la iglesia se veía sumida en un estado de degradación tal, que el párroco Fernando Maraña se vio obligado a contratar las primeras intervenciones de urgencia, a manos de un maestro de obras hasta el momento desconocido, labor por la que se recogen pequeñas cantidades de descargos en el $3^{\circ}$ de los libros de fábrica $^{18}$. Se trataba del autor del proyecto de ampliación de la iglesia, Manuel Pesquera, quien oriundo de la parroquia de Nueva, en el concejo de Llanes, un pequeño pueblo de la costa oriental asturiana, había emigrado a tierras leonesas para trabajar como maestro de cantería.

Las primeras noticias que tenemos de él datan del año 1776, en que realiza, con piedra de las canteras de las Arrimadas, el arco de entrada al cercano templo de Carbajal de Rueda, labor por la que cobra la cantidad de 1120 reales y medio, junto a otros 220 más al año siguiente

Una obra que fue restaurada durante los meses de julio a octubre de 2006 por el Centro de Conservación y Restauración de Bienes Culturales de Castilla y León. TOQUERO MATEO, Javier; SÁENZ DE BURUAGA DANS, Isabel; FRANCO TEJEDOR, Santiago (coords.), Catálogo de obras restauradas (2003-2007). Centro de Conservación y Restauración de Bienes Culturales de Castilla y León, Valladolid, Junta de Castilla y León, 2009, pp. 368-373.

16 AITV. $3^{\circ}$ Libro de fábrica, 2 de julio de 1763, s. f. Mayordomo Manuel del Cano. "Más quince reales para pintar los colaterales del altar mayor".

17 El mayordomo de la cofradía de Sancti Spiritus pagaba un censo de 16 reales y medio, en 1716, a la cercana ermita de San Pedro de los Balmatados.

18 AITV. $3^{\circ}$ Libro de fábrica, 20 de junio de 1774, s. f. Mayordomo Bartolomé Maraña. "Más da en data nobenta y siete reales y veinte y un maravedies de la obra de la iglesia”.

AITV. $3^{\circ}$ Libro de fábrica, 11 de julio de 1776, s. f. Mayordomo Miguel de la Berdura. "Más diez reales de la obra de la iglesia”.

"Más diez y ocho reales que se dieron al maestro". 
por la elevación del pórtico de la citada iglesia; elementos que actualmente se encuentran muy modificados (Fig. 3) ${ }^{19}$.

El 1 de Junio de 1779, en la villa de Gradefes, el llanisco contrataba con el mayordomo José Maraña y el párroco Fernando Maraña la ampliación de la iglesia de Villahibiera, una obra en la que aparece como fiador Agustín Merino, vecino de la localidad de Santibañez de Rueda, junto a Manuel del Cano, natural del municipio ${ }^{20}$.

El trabajo de mampostería y sillería a realizar por el maestro se centraría en "ejecutar dicha obra sacando la piedra para los esquinales o gradas del altar mayor que han de ser tres $y$ la peana y pasales de la entrada de la yglesia, ventanas y pasales" tomando como referencia la longitud del templo, expresada "desde el principio del portal a la entrada de la torre" y la altura hasta llegar a "la soga que baja de la campana"21. Una extensión total de 72 pies de largo y 18 de alto, que equivaldría aproximadamente a unos 20 metros de largo por 5 de alto.

Según se estipula en el contrato, el coste de los portes y materiales de la obra sería por

19 Archivo Histórico Diocesano de León (citado en adelante como AHDL). $1^{\circ}$ Libro de fábrica de la iglesia de Carbajal de Rueda (1740-1842), sig. 1805. Santibáñez de Rueda, 10 de octubre de 1776, fol. 78r. Mayordomo Francisco Urdiales. "Más de el arco de la puerta principal que hizo el maestro Manuel Pesquera mil ciento veinte reales y medio, lo mismo en que se remató su manufactura".

"Más cien varas de piedra que se sacaron en la cantera de las Arrimadas, doscientos reales".

"Más doscientos y cinquenta reales de el porte de ella". "Más ciento y veinte y cinco reales de cal".

"Más treinta y tres reales de el costo, cimbra y postear las vigas".

"Más diez y seis reales de madera y costo para dicha cimbra".

AHDL. $1^{\circ}$ Libro de fábrica, sig. 1805. Santibáñez de Rueda, 11 de octubre de 1777, fol. 79r. Mayordomo Servando Carpintero. "Más ducientos veinte y quatro reales de la manufactura de las puertas de la yglesia". "Más ocho ducados del clavazón de puertas".

"Más de compra de madera y sierra ciento y un reales". "Más ducientos veinte reales de el costo de el pórtico y retexo de la yglesia y veinte y quatro reales de seiscientas texas importa todo ducientos quarenta y quatro reales".

"Más doce reales de clavos para el portal".

"Más de carretajes de madera, arena, barro y limpiar la yglesia cinco ducados".

20 La escritura de la obra de la iglesia ha sido localizada en el Archivo Histórico Provincial de León (citado en adelante como AHPLe). Protocolos Notariales de Diego Otero y Lozano, sig. 1308, caja 806, Gradefes, 1 de Junio de 1779, fols. 143r-143v (véase apéndice documental).

21 Ibídem, fol. 143r.

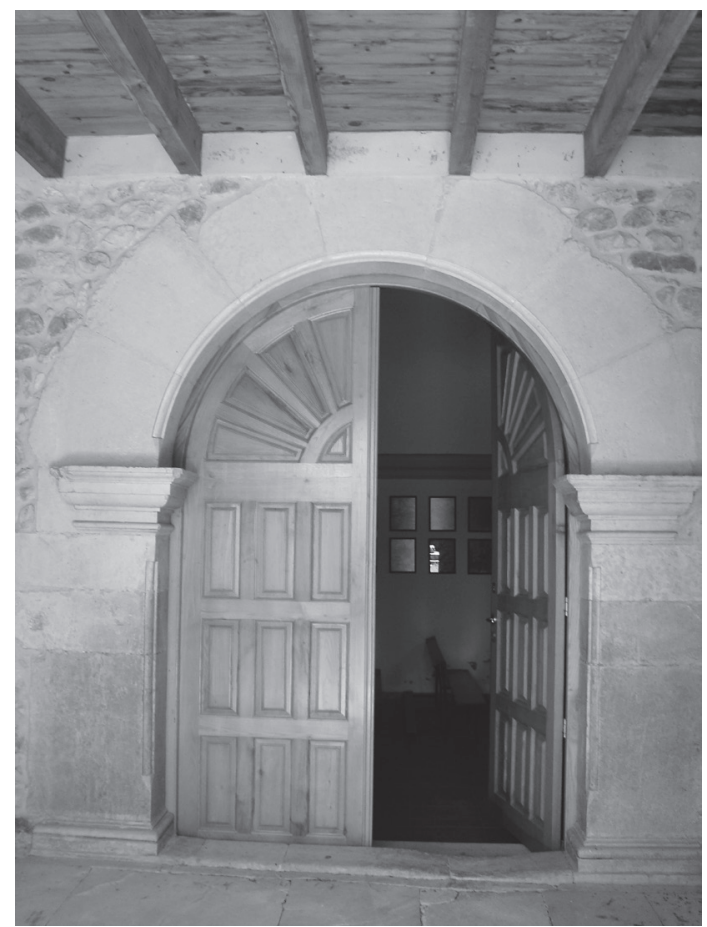

Fig. 3. Arco de entrada a la iglesia de la aparición de San Miguel arcángel de Carbajal de Rueda, León. Fotografía del autor.

cuenta de la iglesia, mientras que la mano de obra correría a cargo del propio Pesquera quien levantaría "el lienzo de la parte de el norte y las demás tapias" hasta completar el nuevo perímetro de la iglesia ${ }^{22}$. El montante ascendería a un total de 3.300 reales, estipulándose el cumplimiento de las condiciones a vista de peritos y saldándose la deuda, previo adelanto de diversos maravedís para la manutención del maestro y sus oficiales, para el 29 de septiembre del mismo año.

Gracias al libro de fábrica de la cercana ermita de San Pedro de los Balmatados, cuya cofradía tenía su sede en la parroquia, conocemos el hecho de que, unos días antes de ajustarse la obra, se encontrasen al frente de la misma el cantero Sebastián Fernández y el maestro de carpintería Manuel Duque ${ }^{23}$, momento a partir del cual dieron comienzo los primeros trabajos,

Ibidem, fol. $143 \mathrm{v}$.

${ }_{23}$ AITV. Libro de la fábrica del glorioso apóstol San Pedro de los Balmatados propio de este lugar de Villa de Viera (1675-1782), 11 de septiembre de 1779, s. f. Mayordomo Francisco Díez. "Más ciento ochenta y cuatro reales que pago para la madera que se traxo de Villapadierna para la iglesia".

"Más doszientos sesenta y dos reales y diez y seis maravedies que importó la sierra los que entrego a los serradores". 
empezándose a anotar descargos por importe de los acarreos y coste de piedra, carros de arena, cal y aserrado de madera procedente de las localidades limítrofes de Villapadierna, Palacio y Quintanilla de Rueda ${ }^{24}$.

"Más quarenta y dos reales y medio que pagó del gasto de los carros de Quintanilla y Palacio que trayeron la madera para la obra".

"Más doscientos y sesenta reales que costaron diez carros de cal para la iglesia".

"Más ciento beinte y siete reales y medio que costaron cinco carros de cal que se compraron dia 18 de mayo". "Más ciento y cuatro reales que dio para acabar de pagar otros cinco carros de cal el dia primero de junio". "Más catorce reales que pagó a Sebastián Fernández por los jornales antes de ajustarse con el maestro". "Más quinientos reales que entregó a Manuel Pesquera maestro de cantería a quenta de los que se le da por la obra de la iglesia".

24 AITV. $3^{\circ}$ Libro de fábrica, 11 de septiembre de 1779, s. f. Mayordomo José Maraña. "Más ciento treinta y un reales de tres chopos que compró en Quintanilla para la iglesia".

"Más setenta y un reales y veinte y cuatro maravedies que pagó a los serradores".

"Más cinquenta reales que pagó por la madera de Antonio Diez de Villapadierna".

"Más setenta y cinco reales y veinte y cinco maravedies que pagó por el vino de los acarretos de la madera".

"Más doscientos y quince reales que pagó de jornales a los carpinteros antes que se ajustase la obra".

"Más doscientos sesenta y seis reales y veinte y cuatro maravedies que pagó por la cal para la obra de la iglesia".

"Más doze reales de dos libras de polbora para sacar la piedra".

AITV. $3^{\circ}$ Libro de fábrica, 25 de octubre de 1780 , s. f. Mayordomo Manuel Ramos. "Más ciento ochenta y tres reales de clabazón para la obra de la iglesia".

"Más otros once reales de clavazón".

"Más ciento diez y seis reales costo de la madera que es traída de Villapadierna".

"Más ciento veinte y siete reales del costo de cinco carros de cal".

"Más ciento ochenta y quatro reales para los carpinteros".

"Más nueve reales de nueve carros de arena".

"Más quatro reales de ir por el clavazón".

AITV. $3^{\circ}$ Libro de fábrica, 10 de octubre de 1781, s. f. Mayordomo Juan Fernández. "A veinte reales de clabazón para la iglesia".

"Más trescientos reales que entregué a los carpinteros de la obra".

"Más ciento y ocho reales que llevó Fermín de Robles en quenta de la obra que hizo en la iglesia".

AITV. $3^{\circ}$ Libro de fábrica, 14 de octubre de 1782, s. f. Mayordomo Clemente de la Puente. "Más da en data dicho mayordomo quarenta y ocho reales que dio a Fermin de Robles en quenta de obra de la iglesia".

"Más veinte $y$ tres reales $y$ veinte $y$ seis maravedies que tubo de costo el barreno que se hizo para sacar la piedra, de yerro, arena y echura".

"Más ciento sesenta y un reales que entregó al maestro de la cantería a quenta de lo que tiene ajustada la obra".
Con motivo de la visita del obispo de León D. Antonio Cuadrillero y Mota, sabemos que el 18 de octubre de 1779 se estaban llevando a cabo las obras, contando la iglesia con un caudal de 7.243 reales, del que distintas cantidades se encontraban "en poder de varios deudores, y son necesarias para la edificación de la iglesia de que se está tratando"25. Es por ello que, a pesar de que los pagos se prolongaron durante al menos tres años más, la fecha de 1779 es considerada el año clave para su ejecución, tal y como se desprende de la cartela epigráfica dispuesta sobre la puerta lateral de entrada al templo; portada de arco de medio punto flanqueado por medias pilastras cajeadas y cobijado bajo estilizada cornisa, en la que reza lo siguiente: "Hizose esta obra a(ño) d(e) 1779 s(ien)do c(ur) a d(o)n Ern(a)ndo Ma(raña)".

Un trabajo que daba comienzo bajo la supervisión de Manuel Pesquera como maestro de cantería y que continuaron Fermín de Robles y Joaquín de la Mata, a quienes se les abonan entre los años 1780 y 1783 cantidades por valor de 1.639 reales, momento en que una vez construida la estructura y cubierta de la iglesia, se produciría la elevación del pórtico exterior ${ }^{26}$.

"Más diez reales de tres dias que se ocupó en ir a cargar los carros que fueron por la madera a Quintanilla". "Más ocho reales que pagó a Manuel Duque maestro de carpintería por dos jornales antes que se ajustase la obra de la iglesia”.

25 AITV. $3^{\circ}$ Libro de fábrica, Villahibiera, 18 de octubre de 1779 , s. f. Visita del obispo de León D. Cayetano Antonio Cuadrillero y Mota. "Iten reconoció las quentas de esta iglesia y las aprobó, declarando caudal de ella siete mil doscientos quarenta y tres reales, y once maravedies, y respecto de que estas cantidades están en poder de varios deudores, y son necesarias para la edificación de la iglesia de que se está tratando, manda que el cura haga liquidación de lo que resultase dever cada uno, en particular con intervención de la justicia de dicho pueblo, para que esta contribución a solicitar su recobro en la inteligencia de que no executándolo, $y$ siendo efectivo este caudal, tendria que contribuir el concejo a dicha obra, como patrono que es. Y para ayuda del coste de dicha obra el caudal y alcance del Santuario de San Pedro de los Valmataos según resulta de la liquidación echa en el año 77, dándole de todo quenta a su iglesia”.

26 AITV. $3^{\circ}$ Libro de fábrica, 8 de diciembre de 1783, s. f. Mayordomo Santos Fernández. "Más da en data trescientos ochenta y quatro reales que gastó en materiales para la obra y jornales de los maestros como consta del memorial de gastos que presento".

"Más se la recibe en data mil seiscientos treinta i nueve reales y veinte $i$ cinco maravedies importe de seis recibos de Fermin de Robles y Joachin de la Mata maestros de la obra de la iglesia”. 


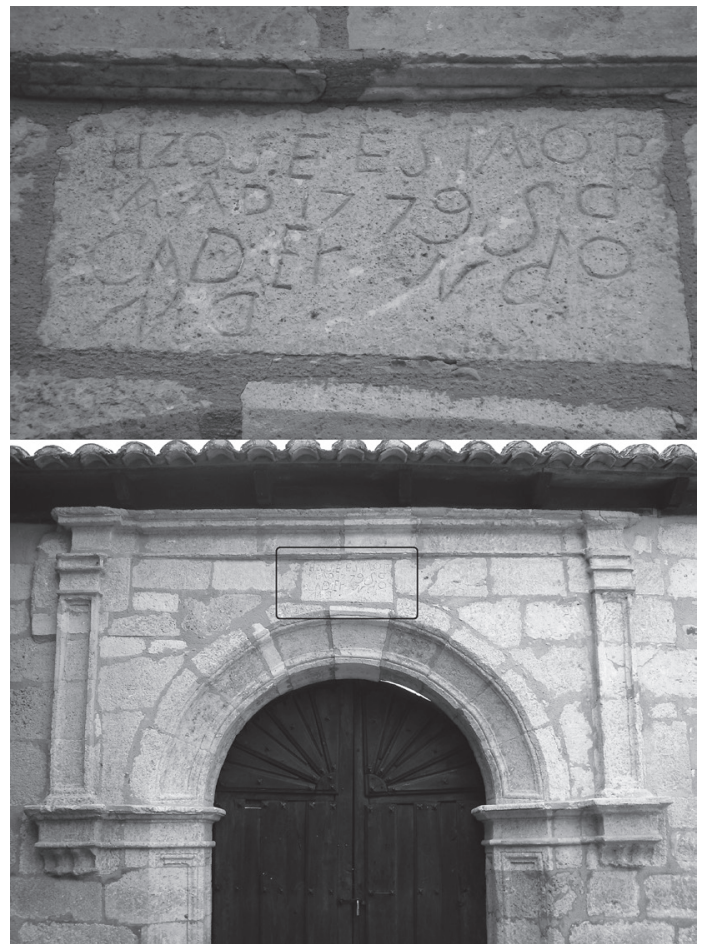

Fig. 4. Inscripción y ubicación de la misma en la portada de acceso a la iglesia de Santo Tirso de Villahibiera. Fotografías del autor.

El 20 de noviembre de 1782, se produce un hecho esclarecedor para la historia constructiva del templo, por el que el notario Diego de Otero y Lozano deja constancia de que las obras se encontraban prácticamente acabadas, ya que en la liquidación efectuada ese mismo año indica "que todo el alcance que queda en limpio es pues de pagada la obra de la iglesia nueva"27. A finales del año 1786 volvería estar abierta al culto, una vez que se descargaban "ciento y quarenta reales que costó el dar de llana y banquear la iglesia" 28 .

El resultado es el de un templo de planta basilical con tres naves, separadas por ocho pilares monolíticos sobre capiteles lisos, cuya triple cabecera presentaba una moldura que ornaba el arco principal y las capillas laterales, correspondiéndose la de la derecha con el acceso a la antigua capilla eremitoria, que hacía las funciones de sacristía y cuya puerta costó 55 reales en el año 1790 (Fig. 5) ${ }^{29}$.

27 AITV. $3^{\circ}$ Libro de fábrica, Gradefes, 20 de noviembre de 1782, s. f. Liquidación de las cuentas de la iglesia por el notario Diego de Otero y Lozano.

28 AITV. $3^{\circ}$ Libro de fábrica, 5 de noviembre de 1786 , s. f. Mayordomo Dionisio Díez.

29 AITV. $3^{\circ}$ Libro de fábrica, 22 de julio de 1790, s. f. Mayordomo Tirso Maraña.

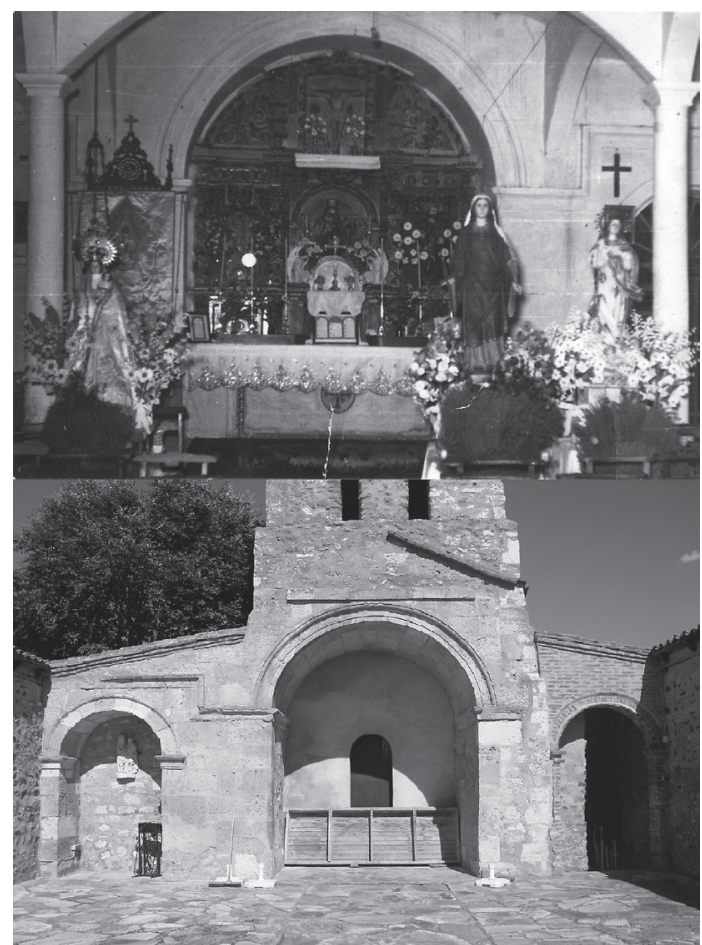

Fig. 5. Imagen interior del altar mayor de la iglesia de Santo Tirso de Villahibiera hacia 1950-1960 y en la actualidad. Fotografía cedida por el párroco D. Calixto Sánchez Tejerina y fotografía del autor.

\section{De la paulatina degradación a la} recuperación de un espacio religioso

Entre los años 1839 y 1849, siendo párroco Juan Díez, se produjeron nuevas reformas en el pórtico, junto a la hechura de la puerta de acceso al mismo, la erección del coro a los pies del templo y la construcción de un confesionario para el culto $^{30}$. Todas estas labores venían justificadas por la constante demográfica de una población de 38 casas y un total de 160 veci-

$30 \quad$ AITV. $3^{\circ}$ Libro de fábrica, 7 de mayo de 1839 , s. f. Mayordomo Francisco Ramos. "Iten ciento cinco reales costó de serrar la madera".

"Iten trecientos setenta que costó de hacer la puerta de la iglesia, portal".

"Iten doscientos setenta y dos reales con veinte y siete maravedies costo de componer el portal de la iglesia de la iglesia y la panera".

"Iten ciento setenta y ocho reales importe de teja y condución".

AITV. $3^{\circ}$ Libro de fábrica, 20 de agosto de 1849, s. f. Mayordomo Dionisio Díez. "Más trescientos cincuenta y nuebe reales que costó acer el coro de la iglesia".

"Más doscientos veinte y nueve reales que costó el hacer el confesonario inclusas algunas tablas y errage".

"Más setenta reales que costó el serrar la madera para el coro".

"Más diez y seis reales que costó hacer la lucera del coro". 
nos, cuya iglesia era conducida "por un cura de ingreso y presentación del concejo y vecinos del pueblo"31.

Desde 1884 hasta 1892, tras la caída del arco y muro sureste, se llevaron a cabo labores de "enladrillar la iglesia", y "reparación esterior de la torre" aprovechando para abrirse dos ventanas de iluminación en la parte sur y una más a los pies, ambas cerradas con rejas ${ }^{32}$. A los continuos retejos y pequeñas reparaciones, les suceden en el tiempo diversas adquisiciones, como la compra de un púlpito por 528 pesetas, constituyendo algunas de las tareas de mejora realizadas por iniciativa del párroco Felipe del Ferrero durante las primeras décadas del pasado siglo $\mathrm{XX}^{33}$.

${ }_{31}$ MADOZ IBÁÑEZ, Pascual, Diccionario Geográfico-Estadístico-Histórico de España y sus posesiones de Ultramar, XVI, Madrid, [s.n.], 1850, p. 152.

32 AITV. $4^{\circ}$ Libro de fábrica, 2 de febrero de 1885 , s. f. Mayordomo Pedro Fernández. "Más ciento cinco pesetas importe de tres mil quinientos ladrillos para enladrillar la iglesia".

"Más ciento treinta pesetas por enladrillar la iglesia, blanquearla con friso, pintar los postes y retejar la torre".

AITV. $4^{\circ}$ Libro de fábrica, 4 de abril de 1889 , s. f. Mayordomo el párroco Juan Diez. "Reparación del templo con licencia del prelado y según recibos de un mil veintiocho pesetas del maestro carpintero según recibo de retejo y blanqueo con reparación esterior de la torre".

AITV. $4^{\circ}$ Libro de fábrica, 15 de febrero de 1892, s. f. Mayordomo el párroco Conrrado Olmo. "Importe de la obra que se hizo en la iglesia, con autorización del prelado y según cuenta documentada que se pone al final de estas cuentas. 1593 pesetas y 84 céntimos".

"Cuenta documentada del importe de la obra que se hizo en la iglesia con autorización del prelado e intervención del señor arcipreste del partido".

"Por poner tres rejas a tres ventanas vid. Recibo no 9". "Al maestro albañil por la obra de manos, recibo no 14 ". "Al maestro carpintero por la obra de manos, vid. Recibo no 16 ".

33 AITV. 5 Libro de fábrica, 2 de enero de 1911, s. f. Mayordomo el párroco Felipe del Ferrero.

AITV. $5^{\circ}$ Libro de fábrica, 3 de enero de 1921, s. f. Mayordomo el párroco Felipe del Ferrero. "Por el decreto de autorización para hacer la obra de la iglesia, 75 reales". "Por un millar de teja, 75 pesetas".

"De gastos que hicieron los que trajeron la teja, 27 pesetas".

"Por medio metro de cal, 12 pesetas".

"Por cuatro sacos de yeso a tres pesetas saco, 12 pesetas".

"Por doscientos adoves, 7 pesetas y 50 céntimos".

"Por dos libras de cola, 2 pesetas".

"Importe de los trabajos que hizo el carpintero, 305 pesetas".

"Por el decreto de autorización para comprar un púlpito, 75 céntimos".
El estado de degradación de la iglesia dio comienzo a finales de la década de los cincuenta $^{34}$, realizándose el último retejo en el año 1.961 , momento en que, con motivo de la construcción de un segundo templo parroquial, acabará cayendo en desuso y en un estado de abandono tal, que llegará a sufrir el desplome de la cubierta. Este nuevo edificio se levantará por iniciativa del obispo de León D. Luis Almarcha Hernández, siendo inaugurado por el prelado en el año 1965 (Fig. 6) ${ }^{35}$.

Finalmente, será en el año 1994 cuando el párroco actual D. Calixto Sánchez Tejerina y varios vecinos de la localidad inicien las obras de restauración de la iglesia, un trabajo fruto del esfuerzo colectivo y de la aportación económica de diferentes instituciones, que durará cuatro años y que se verá consumado el 22 de agosto de 1998, fecha en que fue inaugurada bajo la bendición del obispo de León, D. Antonio Villaplana Molina, destinándose desde entonces a espacio multiusos ${ }^{36}$.

\section{Apéndice documental}

1779, junio, 1. Gradefes.

Escriptura de seguridad para la obra de la Iglesia de Villayviera.

AHPLe. Protocolos Notariales de Diego Otero y Lozano. Sig. 1308, Caja 806, fols. 143r-143v.

"Coste del púlpito quinientas veintiocho pesetas de las cuales se cargan a la fábrica doscientas pesetas según decreto de veinticuatro de noviembre último".

AITV. $5^{\circ}$ Libro de fábrica, 3 de enero de 1942, s. f. Mayordomo el párroco Felipe del Ferrero. "Importe del arreglo de la iglesia con autorización del prelado, inclusos todos los materiales y coste del albañil, 592 pesetas". AITV. $5^{\circ}$ Libro de fábrica, 30 de junio de 1949, s. f. Mayordomo el párroco Felipe del Ferrero. "Por los días de jornal a un carpintero para arreglar el portal de la iglesia, sesenta pesetas".

34 AITV. 40 Libro de fábrica, Villahibiera, 23 de julio de 1959, s. f. Visita del canónigo D. Ángel Castro Gómez. "Todo se encuentra en buen estado de limpieza y se está edificando una iglesia de nueva planta debido al estado ruinoso y mala situación de la vieja".

35 AITV. $4^{\circ}$ Libro de fábrica, 31 de diciembre de 1961, s. f. Mayordomo el párroco Abel Ordás García. "Doscientas tejas y arreglo de tejado iglesia vieja, 480 pesetas”.

36 La restauración se centró fundamentalmente en la consolidación y revoco de los muros del templo, eliminándose por completo los restos del pórtico y dejando a la intemperie la superficie total de las naves. 


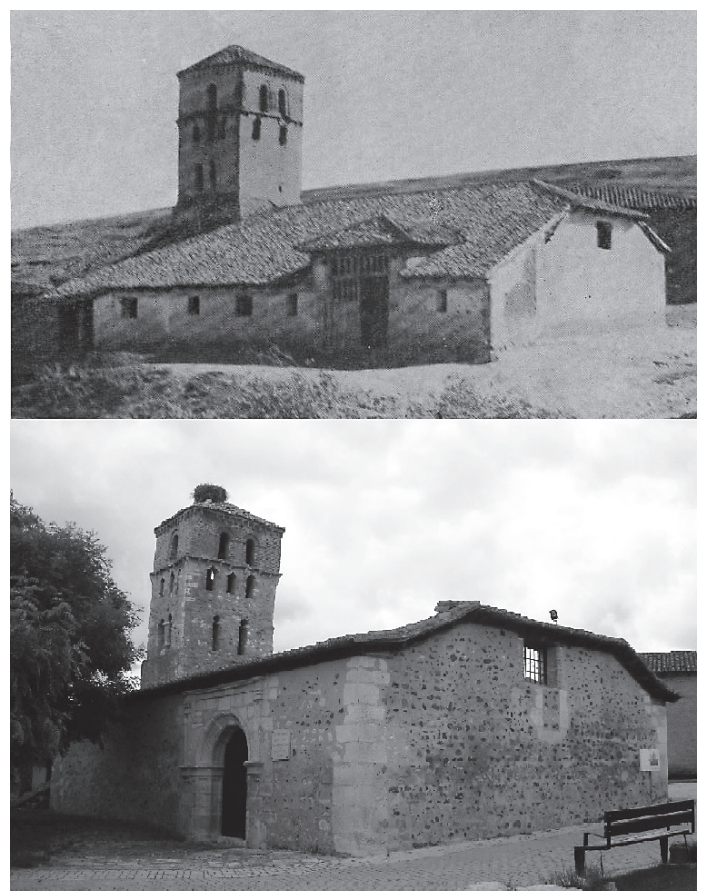

Fig. 6. Vista comparativa del exterior de la iglesia de Santo Tirso de Villahibiera hacia 1936-1945 y en la actualidad. CALVO ALONSO, Aurelio, El Monasterio de Gradefes. Apuntes para su historia y la de algunos otros cenobios y pueblos del concejo, León, Imprenta provincial, 1936-1945, lám. 28 y fotografía del autor.

"Sepase que nosotros Manuel Pesquera vecino de el lugar de Nueba concejo de Llanes principado de Asturias como principal y Agustín Merino vecino de Santibañez como su fiador y principal pagador, juntos por deman común a boz de uno y cada uno de nosotros por hecho y por el todo insolidum renunciando como expresamente renunciamos y Manuel de el Cano vecino de Villaybiera como tal fiador también las leyes de duobus rex de vendi y la authentica presente hoc hita de fide in soribus escursion y division de vienes, depósito de las espensas y demás de la mancomunidad como en ellas y en cada una se contiene decimos que por quanto dicho Manuel Pesquera tiene tratado y ajustado con don Fernando Maraña rector parrocho de dicho lugar de Villayviera y Josef Maraña regidor de el y mayordomo actual de la iglesia parrochial, la fábrica de una obra de mampostería y sillería en la expresada iglesia con las condiciones y grabámenes siguientes: que dicho Pesquera ha de ejecutar dicha obra sacando la piedra para los esquinales o gradas del altar mayor que han de ser tres y la peana y pasales de la entrada de la yglesia, ventanas y pasales desde el principio del portal a la en- trada de la torre hasta llegar a la soga que baja de la campana de su quenta y riesgo: siendo los portes / condición y costo de materiales todo de quenta de dicha yglesia pues dicho Pesquera solo sus manos y jornaleros de el arte; y también ejecutar dicha obra de mampostería que asciende a setenta y dos pies de largo y diez y ocho de alto, el lienzo de la parte de el norte y las demás tapias a correspondiencia incluso la expresada obra de sillería y con dichas condiziones nos obligamos a que se ejecutará dicha obra a vista de peritos y maestros de el arte en la cantidad de tres mill y trecientos reales que se han de satisfacer para el día veinte y nueve de septiembre de este presente año, acudiendo con algunos maravedies antes en quenta de dicha cantidad para la manutención del dicho Pesquera y sus oficiales pena de pagar que pagaremos todas las costas y daños que de lo contrario se recrecieren para cuyo cumplimiento obligamos nuestras personas y vienes muebles $\mathrm{y}$ rayzes presentes y futuros con el poderío a las xusticias de su magestad de nuestro fuero y xurisdizión competentes, renunciamos las leyes $\mathrm{y}$ fueros en fabor con la xurisdición del derecho en forma para que a ello se nos apremie como por sentencia difinitiva pasada en autoridad de cosa juzgada y por nosotros consentida lo otorgamos por firme ante el presente escribano en Gradefes, junio primero de mill setecientos setenta y nuebe años siendo testigos Alonso García Morán vecino de Baldealcon, Pedro Fernández vecino de Villayviera y Santiago Perez residente en este lugar y de los otorgantes a quienes yo el escrivano doy fee conozco, firmaron los que supieron e por los que dijeron no saver uno de los testigos a su ruego y firmé.

Manuel de Pesquera.

Agustín Merino.

Mayordomo Alonso García Morán.

Ante mí, Diego de Otero y Lozano”. 
